\title{
Trabalho e educação: Relações a partir do informacionalismo e do construtivismo
}

\author{
Francisco Coelho Cuogo \\ Luciana Backes
}

Trabalho e educação: relações a partir do informacionalismo e do construtivismo

Resumo: O presente artigo analisa a relação entre trabalho e educação, considerando os reflexos dos interesses capitalistas nas práticas educativas, a partir da sociedade industrial. Neste contexto, as demandas das organizações industriais, visando atender a lógica de acumulação do capital, afetaram a formação dos indivíduos através de uma educação de cunho positivista e pragmática. No entanto, a constituição de uma nova economia informacional e a emergência de uma sociedade com características discordantes da sociedade industrial, potencializadas pelo uso das tecnologias da informação e comunicação, contribuíram para a manifestação e para a expressão dos interesses do cidadão, ainda que não estivessem sob a lógica do capital. Mesmo sendo uma sociedade capitalista, a sociedade informacional, constituiu características que ampliaram as capacidades de comunicação, interação e relação entre os indivíduos, construindo relacionamentos em rede e possibilitando a emergência da subjetividade e, consequentemente, $o$ desenvolvimento da abordagem construtivista na educação. Abordagem esta que se mostra relevante no contexto sobre o qual discorre-se neste artigo, tendo em vista a valorização de um sujeito em ação na construção do conhecimento, sendo um alicerce para as novas formas de interação social e para os processos de aprendizagens presentes na era informacional.

Palavras-chave: Sociedade informacional. Era industrial. Educação; Ciberespaço.

Work and education: relations from informationalism and constructivism

Abstract: This paper examines the relationship between work and education, considering the consequences of capitalist interests in educational practices, from the industrial society. In this context, the demands of industry organizations, to meet capital accumulation logic, affect the formation of individuals through a positivist and pragmatic nature of education. However, the establishment of a new information economy and the emergence of a society with discordant characteristics of industrial society, potentiated by the use of information and communication technologies, contributed to the manifestation and expression of the interests of citizens, even if they were not under the logic of capital. Even being a capitalist society, the information society, constituted characteristics that increased communication skills, interaction and relationship between individuals, building network relationships and allowing the emergence of subjectivity and hence the development of the constructivist approach to education. An approach which is shown relevant in the context on which discusses in this article, in view of the appreciation of a subject in action in the construction of knowledge, and a foundation for new forms of social interaction and the present learning processes in information era.

Keywords: Informational society. Industrial era. Education. Cyberspace.

Esta obra foi licenciada sob uma Licença Creative Commons - Atribuição 3.0 Não Adaptada. 


\section{Introdução}

O desenvolvimento deste artigo contemplou a análise sobre o capitalismo e o trabalho cuja relação se mostra relevante para a compreensão das tendências da educação, bem como de suas práticas ao longo do século XX. O capitalismo no processo de industrialização, as características do trabalho nesse período e as práticas educativas na era industrial são abordadas no tópico dois deste artigo. No tópico três analisamos o surgimento da sociedade informacional. Nesse contexto discorremos sobre a revolução tecnológica e sobre o uso das tecnologias da informação e comunicação TIC's - que estabelecem novos paradigmas na interação social e nos relacionamentos humanos, mediados pela potencialidade das TIC's na construção de uma sociedade emergente que, embora sendo capitalista, apresenta características distintas da sociedade capitalista da era industrial. Consideramos, ainda a relação dessa nova sociedade com o ciberespaço e sua contribuição para o fortalecimento das relações em rede, para a horizontalização do conhecimento e para a ampliação da abordagem construtivista na educação do último quartel do século XX e início do século XXI.

As metamorfoses do sistema capitalista ao longo das décadas de 1960 e 70, a fim de superar a crise pela qual o capital passava, proporcionaram o surgimento de novas formas de produção e de processos produtivos, novas formas de acumulação do capital e uma nova economia. Paralelamente a revolução tecnológica da segunda metade do século XX, sustentada pelas mudanças do capitalismo - na década de 70 - contribuiu para o surgimento de uma nova sociedade: a sociedade informacional. Nesta, o desenvolvimento e o uso das TIC's, a adoção de novas práticas de comunicação e a troca constante de informações foram favoráveis à expansão do construtivismo na educação no último quartel do século XX.

O construtivismo, diferentemente do empirismo - onde o sujeito é condicionado ao objeto, contribuindo para que o capital esteja no centro do processo de formação do sujeito -, prevê um sujeito em ação na construção do conhecimento. Um conhecimento que pode transformá-lo e/ou emancipá-lo, desenvolvendo sua autonomia. Portanto, o construtivismo não atende as necessidades demandadas pelo capital, visto que o foco é o sujeito em ação e o capitalismo, por sua vez, não tem interesse na emancipação dos sujeitos, a fim de manter influência na sua formação. Por isso, numa tentativa de seguir a tendência acadêmica que exaltou o construtivismo, evidenciamos a emergência de diferentes interpretações dadas em relação ao construtivismo na tentativa de adaptar a teoria para atender ao capital, ressignificando a sua compreensão de maneira contraditória, ao colocar os interesses do "capital" como o centro no processo de construção do conhecimento.

\section{Industrialização e educação}

O sistema econômico hegemônico na contemporaneidade - o capitalismo neoliberal - se caracteriza pela lógica da acumulação flexível do capital, tendo como objetivo o lucro em todos os setores da economia. Suas origens se fundem, há pelo menos trezentos anos, com questões políticas e socioculturais, quando a revolução industrial afetava, no século XVIII, as estruturas sociais, os processos produtivos e a distribuição de riqueza. Naquele momento, ocorreram transformações no modo de produção quando o capital empresarial passava a empregar trabalhadores assalariados. E os detentores do capital incrementavam seus lucros através da compra do trabalho 
alheio, visto que os meios de produção e de subsistência ficavam sob o controle do proprietário do dinheiro, e este acumulava capital a partir do excedente do trabalho dos seus empregados. Segundo Hobsbawn (1982), esse processo deu origem ao capitalismo e formou classes distintas de cidadãos, pois, colocava o proprietário dos meios de produção de um lado e os trabalhadores do outro.

As organizações comerciais que emergiam naquele cenário eram marcadas pela divisão do trabalho. E, sob a ótica do capital, este processo foi exaltado na organização do trabalho industrial a partir das perspectivas tayloristas e fordistas. Segundo Smith (1983), a divisão de tarefas aprimoraria as forças produtivas do trabalho, pois ela permitiria identificar a maior destreza existente em cada trabalhador, economizaria tempo - considerando o tempo que seria gasto pelo trabalhador ao passar de uma tarefa para outra - e facilitaria a execução do trabalho, principalmente no uso da maquinaria industrial, visto que o objetivo era abreviar o tempo de produção e ampliar o lucro.

Considerava-se, então, que o trabalhador que demonstrasse maior habilidade e agilidade para determinada tarefa deveria desempenhar sempre a mesma função, acreditando-se que ele desenvolveria seu trabalho com mais qualidade e rapidez. Dessa forma a execução das tarefas seria aprimorada, realizada em tempos cada vez menores e com menos desperdício de material e/ou retrabalho, contribuindo assim para o aumento dos lucros. Por isso, a divisão do trabalho procurava alocar cada trabalhador em tarefas nas quais ele demonstrasse mais aptidão, executando um trabalho cuja característica era a repetição intensa da mesma tarefa. Tal fato foi propício para a produção em série, caracterizada pelas linhas de montagem e pelo trabalho mecanicista, que marcaram a rotina dos trabalhadores dos séculos XIX e XX, visando os interesses capitalistas - ou seja, a obtenção do lucro através do incremento produtivo.

No entanto, a organização do trabalho baseado na separação das funções e especialização das tarefas apresentava benefícios apenas para o capitalista (proprietário do dinheiro e dos meios de subsistência). $\mathrm{O}$ trabalhador era subjugado à um método que exercia total controle sobre o seu trabalho, impondo-lhe uma rígida disciplina na sua rotina e eliminando, assim, todo tempo ocioso durante sua atividade laboral, reduzindo também sua autonomia no ambiente organizacional.

\subsection{O trabalho na era industrial}

As antigas oficinas artesanais, também conhecidas como manufaturas onde o artesão era responsável pelo controle de todo o processo produtivo, foram gradualmente perdendo espaço para as grandes corporações do período industrial. E o artesão - agora obrigado a tornar-se um trabalhador industrial assalariado, visto que o interesse do capital, as novas tecnologias e as máquinas de produção fabril concorriam de forma injusta e opressora com a produção artesanal - era submetido a um trabalho mecanicista. Esse tipo de trabalho não contribuía para a autonomia do trabalhador que era submetido a um controle de tempos e de movimentos na execução das tarefas laborais. O objetivo era sempre adequar o trabalhador a uma rotina, e os modos de produção às necessidades do capital, colocando assim o trabalhador - assalariado - sob o controle do capital. Nesse cenário, o trabalhador era visto como um acessório do processo produtivo, uma vez que as máquinas modernas eram consideradas os principais recursos da produção.

Os interesses do capital se mostraram arbitrários em diversos segmentos da sociedade, não se limitando em oprimir o trabalhador, mas, também, a exercer 
influência sobre a educação. As mudanças no trabalho e nos modos de produção levaram os interesses do capital para dentro das instituições de ensino, a fim de que a educação atendesse às suas demandas. Ou seja, as escolas deveriam aplicar práticas pedagógicas convergentes aos interesses capitalistas, formando indivíduos aptos para o trabalho rotinizado da era industrial, persuadidos também pela política, pela história e pela cultura. A dificuldade inicial, encontrada pelos empregadores, era transformar agricultores e artesãos em trabalhadores de fábricas. Toffler (1995) diz que os primeiros donos das fábricas que se empenharam em industrializar a Inglaterra descobriram que era "quase impossível converter pessoas passadas da puberdade, tiradas de ocupações rurais ou de ofícios artesanais, em operários de fábrica úteis" (TOFFLER, 1995, p. 42).

Por isso, o autor aponta que a educação em massa tinha o propósito de atender as demandas do capital:

Se pessoas jovens pudessem ser preparadas com antecedência para o sistema industrial, os problemas da disciplina industrial seriam enormemente fáceis mais tarde. O resultado foi outra estrutura central de todas as sociedades da Segunda Onda; a educação em massa (TOFFLER, 1995, p. 42).

Logo, desde as séries iniciais já se aplicavam práticas pedagógicas que formassem os estudantes para o trabalho mecanicista, tendo a educação o objetivo de formar os alunos para a atividade industrial e fabril. Crescia, assim, "a oferta de escolas profissionais destinadas a preparar para as tarefas" (ARANHA, 2006, p. 201). Inúmeras eram as instituições de ensino, cuja preocupação central era preparar os alunos sob a perspectiva de um "ensino profissional orientado para a indústria". (ARANHA, 2006, p.204).

Essa educação tinha dois objetivos principais: ao mesmo tempo em que pretendia ensinar levando em conta áreas do conhecimento de interesses do capital, para um grande número de pessoas, pretendia também preparar os jovens estudantes para serem obedientes ao sistema empresarial/industrial a fim de desenvolverem tarefas que compunham a rotina de trabalho naquele cenário. Implicitamente a educação em massa preparava os cidadãos para serem trabalhadores qualificados para a atividade industrial. Assim, os trabalhadores que saíam do meio rural e de suas atividades manuais e artesanais ingressavam numa rotina de tarefas mecanicistas e operacionais que buscavam, por sua vez, dar conta do grande volume de produção em massa, cujo propósito era unicamente o incremento nos lucros.

Os trabalhadores que recebiam essa educação massificada, de caráter pragmático e positivista, eram aqueles que adentravam no contexto industrial desprovidos de recursos e de acesso aos meios de produção. A separação entre quem pensa e entre quem faz era marcada já na formação do indivíduo. Aquele que recebia esse tipo de educação - que instruía o sujeito a obedecer, a repetir e a memorizar - acabava sendo um trabalhador de nível operacional que aprendera as características exigidas pelo ambiente fabril e industrial e tornar-se-ia apto como trabalhador braçal (ou seja, não cognitivo) que se sujeitaria ao trabalho esgotante tipicamente definido pelo mecanicismo.

Diferentemente do cenário constituído pela revolução industrial, nas sociedades agrícolas o aprendizado se dava através do compartilhamento de conhecimentos, valorizando a empiria, as relações humanas e as diversas habilidades que o trabalhador desenvolvia na execução de suas atividades laborais. Cunha (apud ARANHA, 2006, p. 
166) diz que a aprendizagem de ofícios era informal e "desenvolvida no próprio ambiente de trabalho sem padrões ou regulamentações, sem atribuições de tarefas para os aprendizes". A atividade profissional dos artesãos e dos agricultores era caracterizada pela execução de diversas e variadas tarefas durante sua rotina de trabalho e a aprendizagem ocorria na vivência com seus antecessores.

Posteriormente, no período industrial, evidenciou-se um aprendizado reducionista, determinista, apenas baseado na ciência, visando o melhor aproveitamento e rendimento do trabalhador no exercício de sua atividade profissional. Não havia preocupação com o uso de habilidades que o trabalhador dispunha. $\mathrm{Na}$ indústria, cuja atividade era caracterizada pela execução de tarefas repetitivas e com a participação do operário numa única parte do processo produtivo, a aprendizagem ocorria por meio de um instrutor que lhe ensinava o trabalho. Desejava-se apenas a participação do trabalhador através de tarefas braçais, mas sem qualquer valorização para sua participação intelectual no processo produtivo. Por isso, era preciso adaptar o trabalhador habituado com o trabalho manual e artesanal ao trabalho industrial, limitando-o ao desenvolvimento de competências para uma única tarefa ou atividade e super especializando-o em determinadas funções. Essa condição impedia o trabalhador de se desenvolver intelectualmente ou mesmo de fazer uso de outras habilidade e competências.

\subsection{A educação na era industrial}

A educação, atendendo as demandas do capital supria suas necessidades. Schneider (2012, p.48) identifica que "com a Revolução Industrial, os complexos escolares aumentaram, já que o operariado, diferentemente do campesinato, precisava minimamente saber contar, ler e escrever". Como consequência, a educação, nesse período - que tinha características positivistas - ensinava os alunos a olharem a realidade a partir de fatos isolados, garantindo que eles aprendessem aquilo que era relevante para a formação de um cidadão apto a trabalhar nas organizações industriais. Desconsiderando a dialética dos fenômenos sociais, essa tendência na educação se expressava na Pedagogia Liberal e no Tecnicismo. Nestas práticas o conhecimento deveria ser produzido através dos conteúdos ensinados em aula e eram considerados mais importantes que a experiência vivida pelo educando no processo pelo qual ele aprendia. Dessa forma, os liberais contribuíram para manter o saber como instrumento de poder entre dominador e dominado.

A relação do saber como instrumento de poder entre dominador e dominado se fortalecia nos fundamentos positivistas, visto que no período da industrialização, os representantes da educação defendiam "a formação do espírito científico nos estudantes" (SCHNEIDER, 2012, p. 49), deixando de lado temas humanísticos e místicos, partindo para uma formação cujo único conhecimento válido seria a ciência. Para tal condição, Comte entendia que era preciso "a imposição da autoridade na educação, a partir de uma concepção hierárquica entre educador e educando" (CARVALHO; SILVA, 2006, p. 49). Assim, seria possível impor ao estudante o cientificismo através da percepção do educador, sem desenvolver a crítica e a autonomia do aluno, uma vez que a este não era permitido questionar e nem expressarse criticamente.

Para Queiroz e Moita (2007, p. 3): 
A proposta de educação era absolutamente centrada no professor, figura incontestável, único detentor do saber que deveria ser repassado para os alunos. O papel do professor estava focado em vigiar os alunos, aconselhar, ensinar a matéria ou conteúdo, que deveria ser denso e livresco, e corrigir.

Rifkin (2012, p. 134) afirma que "os alunos aprenderam a nunca desafiar a autoridade do professor". Isso fortalecia a ideia de que o professor era o detentor do saber e que a ele cabia a transmissão do conteúdo (CARVALHO; SILVA, 2006). Os alunos, por sua vez, tornavam-se meros agentes passivos deste processo e apenas recebiam do professor os conteúdos como verdades inquestionáveis. Por isso, Libâneo (apud Silva, 2001, p. 2) entende que "a pedagogia liberal sustenta a ideia de que a escola tem por função preparar os indivíduos para o desempenho de papéis sociais, de acordo com as aptidões individuais". Era necessário, então, preparar os estudantes para o trabalho mecanicista que se proliferava nas grandes corporações da era industrial. Formar os alunos para papéis sociais incluía a preparação para o trabalho nas indústrias e fábricas, contribuindo para que as aulas fossem "expositivas, organizadas de acordo com uma sequência fixa, baseada na repetição e na memorização" (QUEIROZ; MOITA, 2007, p. 3).

Repetição e memorização não eram fatores que contribuíam para o desenvolvimento de um senso crítico, mas para o desenvolvimento de um indivíduo capaz de repetir tarefas de forma acrítica, tal como seria exigido dos trabalhadores nas indústrias. As aulas de memorização se propunham a formar sujeitos passivos e menos críticos, visto que os alunos decoravam as informações transmitidas pelo professor, sem questionar ou criticar. Tal fator era propício para a atividade rotinizada, haja vista que o treino intensivo e a repetição eram importantes para o trabalho mecanicista, característico do trabalho naquele contexto. Toffler (1995) afirma que o trabalho de fábrica exigia trabalhadores que se apresentassem na hora, trabalhadores que aceitassem ordens e dispostos a se escravizarem às máquinas ou aos escritórios em tarefas repetitivas.

O trabalhador neste contexto empresarial/industrial era supervisionado constantemente, devendo submeter-se sem questionamentos às ordens dos seus superiores. De acordo com Toffler (1995), a educação passou a ser padronizada, com procedimentos uniformizados, calendário escolar padrão e um currículo escolar e conteúdos programáticos similares para as escolas em diferentes localidades, objetivando um ensino de massa. Por isso, Rifkin (2012, p. 134) afirma que "as escolas se tornaram microcosmo das fábricas", visto que o perfil de profissional requerido pelas empresas naquele período era de um trabalhador submisso, obediente e capaz de ações repetitivas, características que eram reforçadas pelo positivismo na educação através das tendências pedagógicas liberais.

No positivismo destacaram-se duas concepções na educação do século XIX e início do século XX como fruto da exaltação provocada pelo avanço da ciência, que prometia revolucionar o mundo com uma tecnologia cada vez mais eficaz: o cientificismo e o determinismo: o primeiro apresentava uma visão reducionista, defendendo que "a ciência seria o único conhecimento válido"; o segundo atribuía ao comportamento humano as mesmas relações invariáveis de causa e efeito que eram características das leis da natureza" (ARANHA, 2006, p. 205). 
Segundo Aranha (2006) o desenvolvimento da ciência e da técnica trouxe um modo de pensar e agir. A ciência deixou de se comprometer apenas com o conhecimento e passou a se preocupar também com a formação técnica, visando, assim, o aumento de produtividade nas organizações, através de um trabalho realizado por trabalhadores especializados em suas áreas profissionais.

O avanço da tecnologia exigiu a formação de técnicos especializados e, mais ainda, de uma organização do trabalho voltada para o aumento da produtividade, eficiência e eficácia. Para tornar possível essa meta, teóricos propuseram técnicas de racionalização, tais como a do norteamericano Taylor, que no início do século XX teve seu projeto de trabalho parcelado aplicado com sucesso nas fábricas. [...] Essa tendência baseia-se em pressupostos positivistas, e, em nome de um saber científico pretensamente neutro e objetivo, na verdade exerce uma função de controle. (ARANHA, 2006, p. 258).

Paralelamente à Pedagogia Liberal, a teoria behaviorista - também influenciada pelo positivismo - esteve presente na educação dos séculos XIX e XX, defendendo a técnica da instrução programada, "onde as pessoas são educadas de modo científico, por meio de reflexos condicionados" (ARANHA, 2006, p. 257). Tal aspecto tinha um caráter reducionista, uma vez que considerava que os indivíduos aprenderiam de maneira condicionada e, assim, absorveriam conhecimentos com o intuito de se adaptarem ao meio em que vivem. O aluno aprendia de maneira passiva um conhecimento imutável que lhe era ensinado.

E não muito distante dos pressupostos behavioristas, tem-se o tecnicismo como prática pedagógica e fundamentada no behaviorismo, apresentando características mecanicistas no processo de aprendizagem. Segundo Queiroz e Moita (2007, p. 8) a tendência liberal tecnicista tinha como objetivo:

[...] Atender aos interesses da sociedade capitalista, inspirada especialmente na teoria behaviorista, corrente comportamentalista organizada por Skinner que traz como verdade inquestionável a neutralidade científica e a transposição dos acontecimentos naturais à sociedade. O chamado "tecnicismo educacional" [...] constituiu-se numa prática pedagógica fortemente controladora das ações dos alunos e, até, dos professores, direcionadas por atividades repetitivas, sem reflexão e absolutamente programadas.

Por isso, o tecnicismo foi um reflexo do capitalismo industrial, sujeitando a educação aos interesses do capital que tinha por objetivo garantir mão de obra qualificada para atender as demandas do mercado através da produção em série, alocando trabalhadores nas linhas de montagem, que tinham passado pelo processo de ensino presente nas escolas daquele cenário.

\section{A revolução tecnológica e a educação}

A situação econômica do último quartel do século $\mathrm{XX}$ foi decisiva no surgimento de uma nova fase na lógica do capital. A crise do sistema capitalista na década de 70 impulsionou a mudança de um processo de acumulação fordista, típico da era industrial, para um processo de acumulação flexível, típico da era informacional. 
Importante ressaltar que essa condição começa a se estabelecer no Brasil somente a partir de 1990. O informacionalismo emergiu nos países centrais do capitalismo, cujas políticas econômicas assumiam caráter neoliberal a partir de 1970, desenvolvendo-se plenamente até o final de 1990 - especialmente, nos Estados Unidos e Inglaterra - por meio das tecnologias da informação e comunicação. Enquanto o capitalismo ganhava força na economia neoliberal das nações que primeiro aderiram a essa doutrina econômica, no Brasil vivia-se o auge dos governos militares, denominado de país "em desenvolvimento" (subdesenvolvidos), cujo trabalho industrial era marcadamente de nível operacional, contribuindo para sustentar a emergência do neoliberalismo nos países desenvolvidos.

Paralelamente à condição econômica imposta pelo neoliberalismo, as condições sóciotécnicas também impeliram o sistema capitalista para sua reestruturação, construindo um cenário onde as mudanças econômicas eram acompanhadas de avanços tecnológicos. Gradualmente, estas mudanças impulsionaram as transformações para uma nova revolução: a revolução tecnológica. O estímulo dessa revolução vinha desde as descobertas científicas originadas da Segunda Grande Guerra - com a possibilidade de aplicação imediata daquelas descobertas no processo produtivo e no desenvolvimento industrial - até o cenário econômico do final do século XX.

A intensificação da globalização, a ampliação do conhecimento através de pesquisas em diversas áreas do conhecimento, bem como as demandas por tecnologias da informação e comunicação, aumentaram a competitividade de mercado no mundo capitalista. A força da globalização foi favorável para o contexto econômico capitalista, visto que a mundialização das empresas ampliou as possibilidades de novos mercados e de novos negócios. A circulação do capital expandiu-se uma vez que ele poderia ser investido em todo o mundo, a fim de gerar lucros através de sua aplicação em todo e qualquer mercado emergente, não precisando, assim, ficar restrito às saturações dos mercados internos e regionais. Logo, a importância da globalização teve maior peso para as relações econômicas e comerciais cujo benefício se expressou de forma mais intensa para as corporações do mundo capitalista. Segundo Santos (2008), vivemos a globalização do capital, por meio das empresas e do mercado, e não das pessoas.

Os fatores citados no parágrafo anterior favoreceram o surgimento de novos serviços e de produtos que eram desenvolvidos a partir de conhecimentos gerados pela aplicação das tecnologias, agregando valores - subjetivos - aos bens de consumo. Os conhecimentos empregados nos métodos de produção da era informacional auxiliaram na redução de custos e no aumento da lucratividade, permitindo que os meios de produção obtivessem maior acumulação de capital. Desta forma, tornou-se possível realizar investimentos constantes no desenvolvimento de novas tecnologias a serviço da indústria.

A revolução tecnológica, além de ter sido um evento importante na reestruturação do capitalismo e na construção de um modelo de acumulação flexível ${ }^{1}$, deu origem a uma sociedade informacional. Para Castells (1999, p. 50), esta sociedade “originou-se e difundiu-se, não por acaso, em um período histórico de reestruturação

${ }^{1}$ Segundo Harvey (1992) a acumulação flexível é o modo de acumulação do capital que sucede o modelo fordista, da era industrial. Evolução tecnológica constante, intensificação da automação industrial, busca constante por novos nichos de mercado e produção em pequenos lotes, conforme a demanda real, são alguns dos aspectos que caracterizam esse modo de acumulação do capital. 
global do capitalismo, para o qual foi uma ferramenta básica". O desenrolar de uma nova economia, de proporções globais e que se configura como informacional, continua sendo, em seu cerne, uma sociedade capitalista. E, por isso, suas forças de produtividade e de competitividade estão nas capacidades - dos agentes envolvidos nessa economia "de gerar, processar e aplicar de forma eficiente a informação baseada em conhecimentos" (CASTELLS, 1999, p. 119). A geração de novos conhecimentos, a troca e a aplicação da informação são potencializadas no uso de novas tecnologias da informação e comunicação.

As condições tecnológicas naquele momento histórico, além de afetarem a atividade econômica, afetaram também os "hábitos da vida cotidiana" daquela sociedade capitalista e informacional (CASTELLS, 1999, p. 65). Por informacional, entende-se o modelo de desenvolvimento, cuja base está no uso e no compartilhamento da informação.

Segundo Castells (1999, p.53);

Cada modo de desenvolvimento é definido pelo elemento fundamental à promoção da produtividade no processo produtivo. Assim, no modo agrário de desenvolvimento, a fonte do incremento de excedente resulta dos aumentos quantitativos da mão-de-obra e dos recursos naturais [...] No modo de desenvolvimento industrial, a principal fonte de produtividade reside na introdução de novas fontes de energia [...] No novo modo informacional de desenvolvimento, a fonte de produtividade acha-se na tecnologia de geração de conhecimentos, de processamento da informação e de comunicação.

Assim, o desenvolvimento e as manifestações da revolução tecnológica foram "moldados pelos interesses do capitalismo, mas sem se limitarem às expressões desses interesses" (CASTELLS, 1999, p. 50). A sociedade em si, os cidadãos comuns, os indivíduos na sua individualidade também buscavam seus interesses, estabelecendo relações - sociais e comerciais - e afetando as estruturas - hierárquicas e organizacionais - até então existentes. Toffler (1995) considera que no desenrolar da sociedade industrial as mudanças estavam nas mãos do governo, em função do seu poder coercitivo e dos rendimentos de impostos, o que lhe possibilitava "fazer coisas que a empresa não tinha meios de empreender" (TOFFLER, 1995, p. 77). No entanto, a sociedade da era informacional afetou as estruturas da sociedade industrial e abriu “oportunidades fantásticas para a renovação social e política” (TOFFLER, 1995, p. 79).

\subsection{A rede e o ciberespaço}

A consolidação do sistema capitalista, a partir das décadas de 1970 e 80, e o desenvolvimento de novas tecnologias da informação e comunicação, aliadas a uma rede de comunicação global - a internet - contribuíram para o surgimento desse novo sistema econômico e social no período pós-industrial: o informacionalismo. A diferença entre as tecnologias desenvolvidas nesse contexto socioeconômico e aquelas geradas na revolução industrial é que as novas tecnologias - da informação e comunicação convergem para os ambientes virtuais e para as conexões em rede, potencializadas pela internet, trocando informação constantemente. 
A sociedade que emerge da revolução tecnológica, na era da informação, e se destaca pelo modo de desenvolvimento informacional e pela comunicação em rede, não deve ser identificada sob uma perspectiva linear. Estamos construindo uma sociedade pós-moderna, complexa e difusa, não há padrões de comportamento, gostos ou tendências veneradas pela totalidade - ou quase totalidade - dos indivíduos. Preferências e aparências são pessoais, ainda que construídas na interação entre as pessoas desta sociedade, que, pelo desejo de estar-juntas e pelas identificações, formam as tribos. Por isso, articulamos aspectos relacionados ao informacionalismo e à sociedade informacional, com autores que estruturam suas teorias em outros paradigmas, tais como a teoria da complexidade, do pensamento sistêmico e do interacionismo.

Castells (2002) afirma que o sistema comunicacional que vem sendo construído na sociedade informacional é um sistema que fala cada vez mais uma língua universal digital, promovendo a integração global da produção e distribuição de palavras, sons e imagens de nossa cultura, personalizando-o ao gosto das identidades e humores dos indivíduos. E considera, ainda, que as redes interativas de computadores estão crescendo exponencialmente, criando novas formas e canais de comunicação, moldando a vida, e, ao mesmo tempo, sendo moldadas por ela (CASTELLS, 2002).

Esta linguagem universal se caracteriza pela sua interação global através de redes de comunicação e relacionamento numa escala horizontal e com possibilidade de troca de mensagens, dados, imagens e sons. Por isso, pode-se considerar que a internet é também um reflexo do processo de transformação do capitalismo e do desenvolvimento de novas tecnologias, ocupando, no século XXI, um espaço vital na economia e na sociedade contemporânea. De acordo com Castells (1999), o que caracteriza a atual revolução tecnológica não é a centralidade da informação, mas a aplicação da informação para geração de conhecimentos e de dispositivos de processamento e de comunicação. A informação se torna menos centralizada e mais difusa na rede.

Paradoxalmente ao que foi projetado pela sociedade capitalista, homens e mulheres passaram a utilizar as tecnologias de informação e comunicação no seu cotidiano, adaptando o seu uso e transformando a convivência estabelecida nesses espaços. Assim, emergem muitos outros sistemas sociais que se agrupam e reagrupam pelo sentimento de "estar juntos", de identificação e de pertencimento. Segundo Maturana (2002), os seres humanos, no seu viver e conviver configuram espaços de convivência. Para Backes (2011), esses espaços são considerados espaços digitais virtuais, ou seja, TD's que permitem a representação da percepção, a comunicação e interação entre os seres humanos, a fim de que possamos estabelecer as perturbações e a compensação das perturbações. Assim, podemos dizer que são representações das relações sociais, afetando as condutas de comportamento, de relacionamento e de comunicação. Ainda conforme Backes (2011), dessa forma configura-se os espaços digitais virtuais de convivência e constitui-se a convivência de natureza digital virtual. Nesse movimento dinâmico, em que vivemos e convivemos, evidenciamos constantemente a formação da sociedade em rede.

Castells e Cardoso (2005, p.19) definem que:

[...] A sociedade em rede, em termos simples, é uma estrutura social baseada em redes operadas por tecnologias de comunicação e informação fundamentadas na microelectrónica e em redes digitais de 
computadores que geram, processam e distribuem informação a partir de conhecimento acumulado nos nós dessas redes.

Medeiros e Ventura (2008) consideram que as redes são estruturas que se estabelecem por relações horizontais, interconexas e em dinâmicas que supõem o trabalho colaborativo e participativo. As redes se sustentam pela vontade e afinidade de seus integrantes, caracterizando-se como um significativo recurso organizacional, tanto para as relações pessoais quanto para a estruturação social. Na prática, as redes são comunidades que podem ser tanto presencialmente, quanto virtualmente constituídas. E, por isso, as redes podem também constituírem-se e ampliarem-se no ciberespaço. Lévy (1999, p. 94) considera o ciberespaço um ambiente virtual digital que se caracteriza como um "espaço de comunicação aberto pela interconexão mundial dos computadores e das memórias dos computadores". Logo, o ciberespaço denota características favoráveis à construção de redes, visto que descentralização, horizontalidade, participação, colaboração e conectividade são fundamentos das redes e também constituem o ciberespaço. Lévy (1999) considera, ainda, que a rede é o novo meio de comunicação que surge da interconexão mundial dos computadores, transmitindo informações provenientes de fontes digitais, onde existem técnicas, práticas, atitudes, valores e pensamentos que se desenvolvem no ciberespaço.

O ciberespaço, caracterizado pelo ambiente construído na rede, é um canal de comunicação e relacionamento da sociedade informacional. Neste ambiente composto por diversos nós (usuários e seus computadores ou dispositivos de acesso à internet) ocorre a conexão global das sociedades, que constroem um novo espaço de comunicação e socialização, o espaço digital virtual. Informações constantes sobre todas as áreas do conhecimento são trocadas e adicionadas diariamente. Logo, o ciberespaço é característica da sociedade informacional, e as redes que formam o ciberespaço conseguem potencializar a comunicação em espaços digitais virtuais, a interação e a troca de informação, construindo comunidades nos ambientes virtuais digitais que se solidificam pela construção do conhecimento.

Para Lévy (1999), novas pessoas acessam a internet a cada minuto e computadores se interconectam de forma que novas informações entram na rede, ampliando o ciberespaço. Com base nesse crescimento, Lévy (1999, p. 111) considera que "quanto mais o ciberespaço se amplia, mais ele se torna 'universal' e menos o mundo informacional se torna totalizável". Os novos integrantes trazem consigo informações diversas, ampliando ainda mais o volume e a troca de informação.

Em algumas dezenas de anos, o ciberespaço, suas comunidades virtuais, suas reservas de imagens, suas simulações interativas, sua irresistível proliferação de textos e de signos, será o mediador essencial da inteligência coletiva da humanidade. Com esse novo suporte de informação e de comunicação emergem gêneros de conhecimento inusitados, critérios de avaliação inéditos para orientar o saber, novos atores na produção e tratamento dos conhecimentos (LÉVY, 1999, p. 170).

Lemos (2003, p. 11) destaca que a emergência de novas formas sociais, nas décadas de 1960 e 70, e as relações construídas naquele período entre sociedade, economia, cultura e as novas tecnologias foram convergentes em função das 
telecomunicações e das novas tecnologias digitais. Por isso, as características da sociedade informacional e seus reflexos socioculturais contribuíram para um novo cenário na educação. Lévy (1970) aponta que qualquer política de educação teria que levar em conta os efeitos do ciberespaço e das novas sociabilidades nos processos de formação e desenvolvimento dos indivíduos da era pós-industrial.

\subsection{A educação na era informacional}

Os reflexos da sociedade informacional e da constituição do ciberspaço não ficaram restritos ao campo das comunicações e interações sociais na rede. Suas potencialidades foram incorporadas em diferentes domínios do cotidiano, entre eles a educação. $\mathrm{Na}$ educação evidenciamos o movimento de metamorfose de suas práticas pedagógicas de maneira congruente com as novas condições e estruturas sociais emergentes do último quartel do século XX. A partir desse período, paralelamente ao desenvolvimento do informacionalismo e à revolução tecnológica nas nações centrais do capitalismo, o construtivismo, cuja base estava na epistemologia Genética de Jean Piaget, começou a se espalhar pelas escolas.

No Brasil, por exemplo, o construtivismo começou a ser introduzido na educação no final da década de 80 , numa perspectiva de superação dos altos índices de fracasso escolar. A necessidade de superação estava em congruência com as novas tendências paradigmáticas e sociais do final do século XX e início do século XXI, que evidenciava o fracasso da escola tradicional.

O construtivismo, teoria de aprendizagem fundamentada na epistemologia Genética, foi um alicerce para as novas formas de interação social e para os processos de aprendizagens despontados tanto do ciberespaço quanto da sociedade em rede, uma vez que esta teoria de aprendizagem valorizava o aspecto de que os sujeitos constroem conhecimentos variados, por meio da interação. Ou seja, rompia a lógica de que o professor é considerado o único detentor do conhecimento, defendendo que o sujeito aprende através das experiências vividas e da interação com os outros sujeitos e com o conhecimento. Ao interagir com as informações, ele as assimila e as acomoda, adaptando-as em sua estrutura cognitiva. Nesse contexto, o processo de aprendizagem sofre influências diversas das experiências presentes e passadas do sujeito e da interação com o outro e com o meio externo, permitindo que ele construa novos conhecimentos.

Segundo Nodari (2009, p. 57):

O construtivismo difere da escola tradicional porque ele estimula uma forma de pensar em que o aprendiz, ao invés de assimilar o conteúdo passivamente, reconstrói o já existente, dando um novo significado - o que resulta em novo conhecimento.

Portanto, nessa teoria o aluno aprende através da construção de seus conhecimentos por meio da sua ação (cognitiva), o que faz com que todo o saber esteja em constante ampliação. Na perspectiva construtivista, o aluno passa a ser o sujeito da sua aprendizagem. Ele é um sujeito ativo que participa do processo metodológico (NODARI, 2009). Diferente das abordagens anteriores, onde o aluno era simplesmente um receptor das informações transmitidas pelo professor. Para Piaget (2007, p.1) o conhecimento: 
Não pode ser concebido como algo predeterminado nem nas estruturas internas do sujeito, porquanto estas resultam de uma construção efetiva e contínua, nem nas características preexistentes do objeto, uma vez que elas só são conhecidas graças á mediação necessária dessas estruturas, e que essas, ao enquadrá-las, enriquecem-nas.

$\mathrm{Na}$ teoria de aprendizagem construtivista o aluno é o sujeito ativo que estabelece relação de troca com outros sujeitos e com o meio a partir das relações vivenciadas e significativas e a aprendizagem está vinculada ao grau de desenvolvimento já alcançado (NODARI, 2009). Assim, a teoria construtivista considera que não é o professor, exclusivamente, quem está apto para ensinar os alunos, mas, o estudante é apto a aprender e a construir conhecimento.

Portanto, segundo Becker (2012, p. 113),

Construtivismo significa a ideia de que, nada a rigor, está pronto, acabado e de que o conhecimento não é dado, em nenhuma instância, como algo terminado - é sempre um leque de possibilidades que podem ou não serem realizadas. É constituído pela interação entre indivíduos e o meio físico e social, o simbolismo humano e o mundo das relações sociais e se constitui por força de sua ação e não por qualquer dotação prévia, na bagagem hereditária ou no meio, de tal modo que antes da ação não há psiquismo, nem consciência e, muito menos, pensamento.

Então, como pensar o construtivismo, o avanço tecnológico e as mudanças a partir dos novos modelos de acumulação proposto pelo capital?

Nesse contexto emergiram as mais paradoxais propostas para a educação. Vamos destacar apenas duas que mostram o paradoxo entre construtivismo e capitalismo, bem como as diferentes interpretações realizadas por essa teoria de aprendizagem. As aproximações entre o construtivismo e as tecnologias foram muito bem exploradas por meio da Linguagem Logo, uma linguagem de programação interpretada, voltada para todos os níveis de escolaridade. Portanto, é utilizada com grande eficácia em práticas de ensino, bem como por aprendizes em programação de computadores.

A linguagem Logo foi criada em 1967 por Seymour Papert e Wally Feurzeig. Papert desenvolveu um importante trabalho, sistematizado em diversas publicações, devido ao seu trabalho com Jean Piaget (portanto, fundamentado na teoria construtivista). Assim, o ambiente Logo envolve uma tartaruga gráfica, ou seja, um robô que responde aos comandos determinados pelo usuário. Uma vez que a linguagem é interpretada e interativa, o resultado é mostrado imediatamente após digitar-se o comando, a tartaruga realiza a ação programada pelo estudante - incentivando o aprendizado. $\mathrm{O}$ estudante percebe logo em seguida quando escreveu um comando inadequado, portanto aprende com seus erros.

Já numa articulação de cunho mais capitalista que construtivista, surgiu no mercado diferentes softwares educacionais. Atualmente estão sendo comercializados como jogos digitais, numa versão para a aceitação contemporânea da compreensão da "gamificação" na educação. Essas tecnologias digitais exploram atividades tradicionalmente utilizadas pelas pessoas, mas com uma interface digital mais atrativa. Citamos como exemplo caça-palavras, trilhas de caça ao tesouro, questões com respostas de múltiplas escolhas, palavras-cruzadas, operações matemáticas, contagem 
de pontos, ou seja, são propostas ações estimuladas para uma resposta correta. Portanto, muito distante da construção do conhecimento proposta pela teoria.

Essas perspectivas, mesmo que paradoxais, se apresentam no ciberespaço, através das conexões em rede e da troca de informações entre seus diversos nós. O construtivismo (em suas diferentes interpretações) encontra um novo e propício cenário para sua expansão - através da rede - onde os sujeitos se fazem participantes e agentes ativos na troca de informação e na busca por novos conhecimentos, onde podem expressar suas experiências pessoais e individuais, trocando relatos e informações com outros sujeitos que também carregam experiências passadas e presentes. Como a rede se faz pela ação dos participantes e no construtivismo há a necessidade da ação cognitiva do sujeito, essa articulação entre construtivismo e ciberespaço depende fundamentalmente das formas de ação dos sujeitos. Ou seja, são os sujeitos, por meio de suas ações, que determinam a construção do conhecimento ou não, no ciberespaço.

Esse contexto altera a lógica de que o conhecimento está somente no professor e/ou no livro por meio dos conteúdos ensinados, tal como era na pedagogia liberal e nas influências positivistas exercidas na educação tradicional. Contexto em que pode abrir espaço para uso das tecnologias da informação e comunicação na educação à distância, onde o professor se torna um mediador que instiga o estudante a explorar, descobrir, refletir e questionar em busca da aprendizagem. Lembrando que nem toda a educação a distância é fundamentada na teoria de aprendizagem construtivista.

Kuschnir (2011) entende que na educação construtivista o conhecimento é construído através do compartilhamento de ideias, da socialização e da interação com os colegas. Nesse sentido Silva (2006, p.2) considera que o uso da Internet na educação está relacionado aos movimentos do ciberespaço, pois "do novo ambiente comunicacional e cultural que surge com a rede computadores surge um novo espaço de sociabilidade, de organização, de informação, de conhecimento e de educação". Por isso, com o desenvolvimento das tecnologias da informação e comunicação, impulsionadas pela evolução da internet, onde comunicação se dá em duas vias, em caráter interativo, a sociedade informacional encontra no construtivismo fundamentos importantes para o desenvolvimento da aprendizagem na era da informação.

\section{Considerações finais}

Os interesses do capital penetram em todas as esferas da sociedade capitalista, potencializados pela revolução industrial, atingindo diretamente as características das atividades laborais e provocando a alienação do trabalhador em relação ao trabalho.

Os detentores dos meios de produção, no período industrial, tinham como objetivo o lucro e pouca, ou nenhuma, preocupação com as condições de-trabalho, com o cotidiano do trabalhador e suas relações sociais e com o significado do trabalho para sua vida. $\mathrm{O}$ objetivo era o acúmulo de capital, mesmo que o ser humano tivesse que ser subjugado pela maquinaria e pela tecnologia que determinavam a organização do trabalho nas empresas naquele momento.

A ascendência dos interesses do capital, contudo, transcendiam seus efeitos determinantes sobre os processos produtivos e sobre o ambiente profissional das empresas e indústrias. Sua intensidade penetrava em diversos segmentos daquela sociedade, chegando a afetar a educação. As práticas pedagógicas seguiam uma orientação positivista, visando preparar os alunos para serem futuros trabalhadores. 
Alunos que não questionassem, que fossem capazes de memorizar e de obedecer eram os futuros trabalhadores esperados nas corporações daquele período. Trabalhadores que estivessem aptos para serem subjugados pelo trabalho rotinizado e mecanicista cujas características beneficiavam apenas as minorias que detinham as máquinas e os meios de produção e acumulavam riquezas através da contratação do trabalho alheio.

As mutações do sistema capitalista a partir da década de 1970, cujo propósito era superar sua própria crise, impulsionaram a ocorrência de uma nova revolução no último quartel do século XX. A revolução tecnológica, além de mudanças sociopolíticas e econômicas - tal como foi com a revolução industrial - afetou e afeta as estruturas sociais e as condições de trabalho. No entanto, as novas tecnologias produzidas por essa revolução contribuem para a construção de uma nova sociedade - a sociedade informacional. E, ainda que esta sociedade continue a ser regida pelo capitalismo, as tecnologias da informação e comunicação potencializam um novo tipo de relação entre os indivíduos, contribuindo para o fortalecimento da expressão de seus interesses. Interesses que nem sempre são compatíveis com os interesses do capital.

Assim, estamos num período de transformações, favorável para o desenvolvimento da autonomia do cidadão tanto no ambiente profissional, quanto no ambiente acadêmico/escolar. Nesse cenário, a educação incorpora a teoria construtivista em suas práticas pedagógicas, mesmo que em alguns casos maneira paradoxal, contribuindo para uma formação que está vinculada a interpretação de quem está na educação. Como o construtivismo é uma teoria que pode estar relacionada aos paradigmas emergentes, muitas outras possibilidades começaram a emergir, tais como o interacionismo, pensamento sistêmico, teoria da complexidade, entre outras perspectivas. Logo, as tecnologias da informação e comunicação potencializam a construção de novos espaços digitais virtuais que se utilizam das tendências informacionais. Ou seja, a valorização da opinião do indivíduo, a valorização dos seus conhecimentos e experiências, e a construção de novos conhecimentos através de relações em rede.

\section{Referências}

ARANHA, M. L. História da Educação e da Pedagogia: Geral e Brasil. São Paulo: Moderna, 2006.

BACKES, L. A Configuração do Espaço de Convivência Digital Virtual: A cultura emergente no processo de formação do educador. Tese de Doutorado. Programa de PósGraduação em Educação - Universidade do Vale do Rio dos Sinos, UNISINOS. São Leopoldo, 2011.

BECKER, F. Educação e Construção do Conhecimento. 2 ed. Porto Alegre: Penso, 2012.

CARVAlHO, A. B de C. SILVA, W.C. L da. Sociologia e Educação. São Paulo: Avercamp, 2006.

CASTELLS, M. A Sociedade em Rede: A Era da Informação; v. 1. Ed. São Paulo: Paz e Terra, 1999.

CASTELLS, M. O poder da identidade: A era da informação: economia, sociedade e cultura; v.2. São Paulo: Paz e Terra, 2002. 
CAStells, M. CARDOSO, G. A Sociedade em Rede: Do Conhecimento à Ação Política. Imprensa Nacional - Casa da Moeda, 2005.

HARVEY, D. Condição Pós-Moderna. São Paulo: Loyola, 1992.

HOBSBAWM, E. J. A era das revoluções: Europa 1789-1848. Rio de Janeiro: Paz e Terra, 1982.

KUSCHNIR, A. N. Quem, quando, onde e por quê? A sala de aula sob uma perspectiva sociohistórica. Ensaio da Revista Pesquisas em Discurso Pedagógico - Fascículo no 1. PUC-Rio, 2011.

LEMOS, A. (org.). Olhares sobre a Cibercultura. Porto Alegre: Sulina, 2003.

LÉVY, P. Cibercultura. São Paulo: Editora 34, 1999.

MATURANA, H. A Ontologia da Realidade. Belo Horizonte: UFMG, 2002.

MEDEIROS, Z. - VENTURA. P. C. S. Cultura tecnológica e redes sociotécnicas: um estudo sobre o portal da rede municipal de ensino de São Paulo. Revista Educação e Pesquisa. São Paulo, v.34, n.1, p. 063-075, jan./abr. 2008

NODARI, L. C. L. Psicologia e Educação. Ijuí: Ed. Unijuí, 2009.

PIAGET, J. Epistemologia genética. São Paulo: Martins Fontes, 2007.

QUEIROZ, C. MOITA, F. Fundamentos sócio-filosóficos da educação: As tendências pedagógicas e seus pressupostos. Natal: UEPB/UFRN, 2007.

RIFKIN, J. A Terceira Revolução Industrial. São Paulo: M.Books, 2012.

SANTOS, M. Metamorfoses do Espaço Habitado. 6. ed. São Paulo: Editora da Universidade de São Paulo, 2008.

SATO, M. O que são redes? REBEA - Rede Brasileira de Educação Ambiental. Publicado em 2003.

SCHNEIDER, L. A. História da Educação. Ed. Intersaberes. Curitiba, 2012.

SILVA, D. B. da. As principais tendências pedagógicas na prática escolar brasileira e seus pressupostos de aprendizagem. Revista Linguagens \& Cidadania. Edição 3. Janeiro de 2001. UFSM: Universidade Federal de Santa Maria. Disponível em: <http://coral.ufsm.br/lec/01_00/DelcioL\&C3.htm>. Acesso em: abril de 2013.

SILVA, A. M. P. da. Processos de ensino-aprendizagem na Era Digital. Universidade Aberta: Biblioteca online de Ciências da Comunicação, 2006. Disponível em: http://www.bocc.ubi.pt.

SMITH, A. A Riqueza das Nações. Coleção: Os Economistas. Volumes 1. São Paulo: Abril Cultural, 1983.

TOFFLER, A. A Terceira Onda. Rio de Janeiro: Record, 1995. 